\title{
Society's Role in Tolstoy's Anna Karenina
}

\section{Hannah Su}

Although many critics argue that Leo Tolstoy's Anna Karenina was a critique on faith, morals, or love, each of these topics takes place against the backdrop of society, which ultimately forms Tolstoy's greatest concern in the novel. Society, and how Anna is shaped and affected by it, is the driving force throughout this story of individual fates. The fickle nature of society in the novel is demonstrated through Anna's emotionally honest actions throughout, as well as Vronsky's relation to them. Her death was ultimately detrimental to her message: even though Tolstoy made Anna a powerful protagonist, a 19th-century woman constantly striving toward her personal goals, Anna's argument of valuing honesty and action is muddled by her fate. However, if readers understand that it was the silent observer of society that caused Anna's death, the themes in Tolstoy's novel and the message he meant to convey with her death become clear. A real life, one honestly progressing along an imperfect path-as all natural lives-should never be something controlled by society.

\section{| Introduction}

Russian high society during the 19th century was perceived by some artists and intelligentsia as caught up in vanity and lying for the sake of achieving order within the upper class. Leo Tolstoy clearly demonstrates throughout his novel Anna Karenina how these very qualities of society played a role in the protagonist's unjust and tragic fate. Although society saw adultery as common, Anna alone was punished for being emotionally honest by choosing Vronsky and publicly divorcing her husband. Tolstoy goes on to depict how the society around Anna was fickle in nature. Because those surrounding Anna operated within a closed system of conventional cultural norms, they grew discomforted by the uninhibited practices of Anna's life.

In the article "Russian Views of Anna Karenina, 1875-1878," A. V. Knowles states that Anna Karenina, "besides treating the wider problems of the purpose of life, the question of 
love and marriage, the attitudes between a husband and wife, and of both to their children, and the effects of a breakdown of a marriage upon the parents, [had] something to say about contemporary problems-the place of women in society..." (Knowles 301). Knowles continues to argue how the depiction of Anna as one of the central protagonists was helpful to society's view on women during this time period, given Anna's pursuit of emotional honesty. According to Forrester's chapter in Women in Nineteenth-Century Russia: Lives and Culture, Russian society during the 19th century tended to approach women in one of two ways: they either treated women as conniving beings in pursuit of superficial goals and villainized them, or they treated women as unambitious creatures confined to small domestic societies and patronized them. However, Anna was a character of realistic depth and admirable nature; she possessed principled goals, and an unwavering empathy that made her character impactful throughout the novel. The effect of Tolstoy writing Anna as a central protagonist forced contemporary society to understand that women could and should be seen as individuals in their own right, with equal importance to their pursuits and goals.

While Tolstoy made the right decision in choosing Anna as one of the main protagonists in the novel, worthy of naming it after her, the decision to remove her from any fulfilling conclusion may have been more harmful. Society during the time was normalized to adultery, yet Tolstoy deprived Anna as a character from the satisfaction of achieving positive resolution. If Anna as a character reflected the mores of contemporary readers, then Tolstoy's message might be interpreted one of two ways; either society was wrong, or Anna was wrong. Because her character was killed in the end, critics question whether Anna's fate was justified if she was the one who succumbed to the pressure.

In "Scapegoating, Double-Plotting, and the Justice of Anna Karenina," Catherine Brown outlines the various answers to the question of whether Anna deserved her fate at the end of the novel. The article discusses the notion of Anna's role as a scapegoat to persecution in both the novel and the real world when it was published. In other words, Anna's sacrifice led to her condemnation in real and imaginary societies, even though adultery was as normal then as it is today. This then, Brown argues, proves the point that Tolstoy was making: if a woman chooses to defy societal expectations, society will take those individual actions as personal offenses and take every opportunity to condemn her in order to make themselves appear more important and virtuous.

Society's reply of judging Anna for her decisions indeed proves the point Tolstoy illustrated about the connection between the shallowness of Anna's fictional society and the superficiality of real life around the reader. In a way this breaks the barrier between the fictional work and the reader, but what Tolstoy is saying about Anna's fate is a point about society. By being so focused on perceptions, those individuals in society overlook their own inadequacies. According to Tolstoy, those who ignore their own flaws are inclined to condemn the flaws of others because it brings fulfillment. It is due to the comfort of repetition that society remains able to survive as a force against natural humanity.

This point about society is also made by Curt Whitcomb in "Treacherous 'Charm' in Anna Karenina." Whitcomb writes how members of society in Anna Karenina "become watchers rather than doers, and thus, unknowingly confuse the aesthetic practice of depicting with the unframeable process of living" (Whitcomb 214). He describes how Levin and Kitty, with their happy ending, achieved a resolution by not binding their sense of self to society's perceptions of who they were. Although they are shown to be active within society, Levin is self-described 
as not fitting within any social class, which does not show itself to be a problem within the novel. However, it is Anna's preoccupation with her perception by others in society that changed her and prevented her story from achieving a sense of resolution. Ultimately, it is the silent observer of society that leads to Anna's unfortunate end.

The sense of the silent observer of society being the real culprit to humanity is something that connects again with Russia during this time period. Tolstoy was born in 1828, nine years before the poet Alexander Pushkin died in infamy and ridicule. Because Pushkin's work rose to fame so quickly, the public grew bored of him just as quickly. Tolstoy would have grown up hearing from other artists and writers about how Pushkin's infamy was due to society's problems, not his own. By the time Anna Karenina was published in 1877, Russia was experiencing a revolutionary movement in which new radicalism challenged society, causing civil unrest as the educated youth began taking action and advocating for change. Thus Tolstoy painted society as the driving force in this novel around which Anna Karenina is centered. Another researcher agrees with this point. In "Tolstoy and Anna Karenina," Clarence Manning argues, "Morality and happiness depend on society and we should be corrupt as society sanctions, no more" (Manning 509). Through the details given in the novel, Manning explains how Anna's fate broke the sanction of corruption that society allowed long before her demise. The point was that life itself should not be something so easily controlled by society.

Tolstoy did not live on a path that others easily understood. He came from a famous aristocratic family before becoming orphaned at nine, was excommunicated from the church and rejected tradition and convention. Tolstoy's rejection of norms is important to understanding Anna Karenina because the way in which Tolstoy maneuvered Anna through her rejection from society is indicative of the message he conveyed to readers. Tolstoy's message to the reader, his didactic moral that he showed through his realistic and deeply psychological portrayal of societies, is to understand the sincerity of a life lived along an imperfect path.

Due to Tolstoy's deep psychology embedded within the novel as well as his scrutiny as an artist, Gorodetzky notes, "Anna Karenina can claim a central place in the works of Tolstoy, not because it is greater than his other books, but because it displays Tolstoy both as an artist and as a thinker" (Gorodetzky 121). However, the questions are still raised by readers: "can this be reconciled with the portrait of a woman more pitiable than guilty?" (Gorodetzky 122). He illustrates the full life of the author while pondering the question of Anna's innocence in the matter of her death, or of whether her character deserves justice.

However, Anna is more than a portrait of a pitiable woman; she is a woman so natural to understand within the time period, that her character is accentuated by the realism of her soul. Anna's portrait is one of a woman who, after having initially flourished in the high society she believed would fulfill her, finds that her emotional honesty cannot allow her to maintain satisfaction with her situation. Yet it is because of that emotional honesty and value of love that Anna falls prey to society. Her emotional honesty and values are the reasons why her death is so unjustified.

On the topic of unjustified deaths in Anna Karenina, Gorodetzky also notes how Anna's character arc is measured and foreshadowed in the racehorse Frou-Frou. In the novel, Anna's lover Vronsky participates in horse racing, a pastime which he is proud of and does for sport. He rides a new horse, a mare named Frou-Frou who develops a quick affinity with Vronsky, 
and together they participate in, and almost win, a race. However, due to a wrong move on Vronsky's part, Frou-Frou breaks her back and is put down shortly afterward. This devastates Vronsky, and sticks with him, but he moves on with life.

Frou-Frou and Vronsky's relationship can draw a direct parallel to Anna and Vronsky's relationship, but also the idea of horse racing itself and Frou-Frou's part in it is symbolic of society and Anna's part in it. A renowned horse racer, Vronsky holds an equally esteemed position in society. During the late 19th-century setting of Anna Karenina, horse racing is viewed by the aristocracy as exciting and therefore a part of society similar to modern sports. Vronsky's use of Frou-Frou during their time together was fast and exciting before causing harm to her; ultimately, Vronsky found himself unable to keep up with Frou-Frou's pace, and abandoned her once the audience and those nearby led him away from her. This imagery is parallel to Vronsky's actions prior to Anna's suicide, after which he is led to join the Slavic uprisings. Nevertheless, it is the death of Frou-Frou that causes Vronsky to recall how, "the memory of that race remained for long in his heart as the cruelest and bitterest memory of his life" (Tolstoy 200). The view of women as dispensable, and their deaths as unimportant, is not what Tolstoy is allowing with Anna Karenina. Because Frou-Frou's handler had instructed Vronsky to "let her choose as she pleases," and Vronsky accidentally held her back, causing her death, the reflection in Anna's story speaks to the importance of her death and society's responsibility for it. Even though she dies before the end of the work, the weight of Anna's presence is superimposed by the eponymous title of the novel.

Critics argue that the biggest themes in Tolstoy's novel are concepts such as love, faith, or perception, even agriculture. None of these are wrong. Each of those topics are addressed in Tolstoy's Anna Karenina, and each one developed throughout the novel in such a way that it may be difficult to determine the most important theme conveyed by Tolstoy. Love is shown through Kitty and Levin, the other principal characters, with faith shown very clearly through Levin's spiritual question taking up the latter part of the novel. Perception is developed through Anna's character, both in how she perceives the world and how she is perceived by it. Likewise, agriculture can be seen as the biggest theme in the novel due to its extensive jargon and chapters which take place among the peasantry.

However, it is clear that each of these topics takes place against the backdrop of society. Each time a character is introduced in the novel, their titles come after a description of the society surrounding them. Each character grows, develops, and acts according to, and in spite of, societal expectations. Tolstoy illustrates the parallels of expectations, superficiality, and perceptions as they exist in society around the reader. By shining a light on the dire consequences of a fickle society, Tolstoy demonstrates the far-reaching hand that society has in one's fate. If Tolstoy had given Anna a positive outcome to the pursuit of her values in spite of societal expectations, he could have illustrated the true strength of emotional honesty and valuing love in one's life. Instead, the death of her character serves as a warning: if society continues to prioritize values of social order and conventional norms, the human values of love and honesty will perish. In Anna Karenina, Tolstoy clearly illustrates the role of society in Anna's demise; through this, he shows the value of individual fates, the consequences of defying expectations, and the ambivalent nature of society as a force to impose and uphold them. 


\section{References}

Brown, Catherine. "Scapegoating, DoublePlotting, and the Justice of Anna Karenina." The Modern Language Review, vol. 106, no. 1, 2011, pp. 179-194. JSTOR, www.jstor.org/ stable/10.5699/modelangrevi.106.1.0179.

Forrester, Sibelan. "1. Introduction: Framing the View: Russian Women in the Long Nineteenth Century." Rosslyn, Wendy, and Alessandra Tosi. Women in Nineteenth-Century Russia: Lives and Culture. Cambridge: Open Book Publishers, 2012. pp. 1-17. Web. http://books. openedition.org/obp/1239.

Knowles, A. V. "Russian Views of Anna Karenina, 1875-1878." The Slavic and East European Journal, vol. 22, no. 3, 1978, pp. 301-312. JSTOR, www.jstor.org/stable/307531.

Manning, Clarence Augustus. "Tolstoy and Anna Karenina." PMLA, vol. 42, no. 2, 1927, pp. 505-521. JSTOR, www.jstor.org/stable/457520.

Tolstoy, Leo. Anna Karenina. Trans. Richard Pevear and Larissa Volokhonsky. Penguin, 2004.

Whitcomb, Curt. "Treacherous 'Charm' in Anna Karenina." The Slavic and East European Journal, vol. 39, no. 2, 1995, pp. 214-226. JSTOR, www.jstor.org/stable/309374. 
